ISSN : 2580-3220, E-ISSN : 2580-4588

J. Mandiri., Vol. 4, No. 2, Desember 2020 (210 - 221)

(C)2018 Lembaga Kajian Demokrasi

dan Pemberdayaan Masyarakat (LKD-PM)

DOI : https://doi.org/10.33753/mandiri.v4i2.129

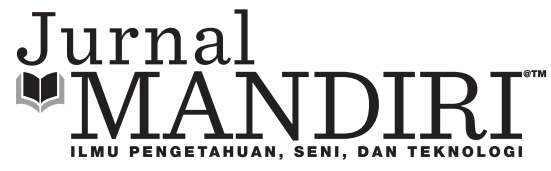

\title{
Pengaruh Pengembangan Karir Terhadap Kinerja Karyawan Pada PT Bank CIMB Niaga Cabang Pondok Indah, Jakarta Selatan
}

\author{
Zackharia Rialmi \\ Fakultas Ekonomi dan Bisnis, Universitas Pembangunan Nasional Veteran Jakarta \\ zac_rialmi@upnvj.ac.id \\ Papang Patoni \\ Fakultas Ekonomi, Universitas Pamulang \\ papang@gmail.com
}

\begin{abstract}
Abstrak
Penelitian ini dilakukan untuk menguji pengaruh pengembangan karir terhadap kinerja karyawan pada PT Bank CIMB Niaga Cabang Pondok Indah. Metode penelitian yang digunakan adalah metode kuantitatif dengan penggunaan data primer dan sekunder. Populasi dan sampel adalah sebanyak 40 responden, yang merupakan karyawan Divisi Credit Card dari PT Bank CIMB Niaga Cabang Pondok Indah. Hasil penelitian dengan menggunakan korelasi Pearson Product Moment menunjukan bahwa pengembangan karir memiliki hubungan yang lemah dengan kinerja karyawan, dengan diperolehnya koefisien korelasi $r=0,2487$. Kontribusi pengaruh dari pengembangan karir terhadap kinerja karyawan dengan nilai koefieien determinasi $r^{2}$ sebesar 6,18\%, sedangkan sisanya sebesar 93,83\% dipengaruhi oleh faktor-faktor lain yang tidak diteliti di dalam penelitian ini. Hasil uji signifikansi menunjukan bahwa $t_{\text {hitung }}<t_{\text {tabel }}$ yakni 0,3820<2,0262, sehingga dapat disimpulkan bahwa pengembangan karir (X) tidak memiliki pengaruh yang signifikan terhadap kinerja karyawan (Y) pada PT Bank CIMB Niaga Cabang Pondok Indah.
\end{abstract}

Kata Kunci : Pengembangan Karir, Kinerja Karyawan

\begin{abstract}
This research was conducted to examine the effect of career development on employee performance at PT Bank CIMB Niaga Pondok Indah Branch. The research method used is a quantitative method with the use of primary and secondary data. Population and sample are 40 respondents, who are employees of Credit Card Division of PT Bank CIMB Niaga Pondok Indah Branch. The results of research using the Pearson Product Moment correlation show that career development has a weak relationship with employee performance, by obtaining a correlation coefficient of $r=0.2487$. The contribution of the influence of career development on employee performance with a coefficient of determination of $r^{2}$ is $6.18 \%$, while the remaining $93.83 \%$ is influenced by other factors not examined in this study. The results of the significance test show that $t_{\text {count }}<t_{\text {table }}$ is 0.3820 $<2.0262$, so it can be concluded that career development $(X)$ does not have a significant effect on employee performance (Y) at PT Bank CIMB Niaga Pondok Indah Branch.
\end{abstract}

Keywords : Career Development, Employee Performance 


\section{PENDAHULUAN}

Dewasa ini persaingan global menuntut setiap organisasi untuk mampu memaksimalkan seluruh faktor produksi yang dimilikinya untuk lebih kompetitif sehingga dapat memperoleh laba maksimum di dalam usaha mempertahankan eksistensinya. Salah satu faktor produksi terpenting adalah sumber daya manusia sebagai penggerak utama suatu institusi dan organisasi. Faktor produksi ini bahkan tidak lagi dikatakan sebagai sumber daya, tetapi menjadi modal bagi organisasi untuk mencapai tujuannya. Pengembangan karir merupakan salah satu stimulus yang ditawarkan oleh perusahaan atau organisasi untuk menarik talenta dari luar, serta mempertahankan talenta atau karyawan terbaik yang mereka miliki.

T Hani Handoko dalam (Sunyoto, 2012) menjelaskan pengertian karir meliputi (1) karir sebagai suatu urutan promosi ke jabatan-jabatan yang lebih menuntut tanggung jawab atau lokasi yang lebih baik dalam atau mengulang tingkatan hubungan kerja selama kehidupan kerja seseorang, (2) karir sebagai penunjuk pekerjaan yang membentuk pola kemajuan sistematik yang jelas bagi kehidupan kerjanya, dan (3) karir sebagai sejarah pekerjaan seseorang atau serangkaian posisi yang dipegangnya selama kehidupan kerjanya.

Marwansyah (2012:208) menjelaskan bahwa karir adalah kegiatan pengembangan diri yang ditempuh oleh seseorang untuk mewujudkan rencana karir pribadinya. Sedangkan Sunyoto (2012:164) mengatakan bahwa karir adalah peningkatan pribadi yang dilakukan seseorang untuk mencapai suatu rencana karir. Pengembangan karir ini tidak akan terlepas dari penilaian dan pengukuran kinerja yang dilakukan oleh perusahaan. Karyawan yang memiliki performance baik, akan memiliki kesempatan untuk mendapatkan pengembangan karir yang lebih baik.

Undang-undang nomor 13 Tahun 2003 tentang Ketenagakerjaan Pasal 1 ayat (9) menjelaskan bahwa pengembangan karir tidak dapat dipisahkan dari pelatihan kerja yang mengandung arti sebagai keseluruhan kegiatan untuk memberi, memperoleh, meningkatkan serta mengembangkan komptensi kerja, produktivitas, disiplin, sikap dan etos kerja pada tingkat keterampilan dan keahlian tertentu sesuai dengan jenjang dan kualifikasi jabatan atau pekerjaan.

Penilaian kerja di atas akan membuka kesempatan yang sama bagi seluruh karyawan untuk mengembangkan karirnya. Pengembangan karir juga merupakan bagian dari kompensasi. Kompensasi yang dimaksud di sini, tentu saja adalah kompensasi non finansial. Kompensasi non finansial adalah kepuasan kerja yang diperoleh oleh seseorang dari pekerjaan itu sendiri atau dari lingkungan psikologis di mana orang itu bekerja. Dengan kata lain, kompensasi balas jasa selain berupa uang (finansial). Oleh karena itu tipe kompensasi non finasnial meliputi kepuasan yang didapat dari pelaksanaan tugas yang signifikan yang berhubungan dengan pekerjaan (Riyadi, 2011:41).

Pekerjaan yang menantang dan menarik serta adanya pengembangan karir yang ditawarkan oleh perusahaan dan organisasi tentu saja akan meningkatkan komitmen dan motivasi kerja dari karyawan itu sendiri. Program pengembangan karir ini sendiri dan penilaian kerja yang berorientasi kepada karir merupakan 2 (dua) komponen penting dalam proses ini. Dari sisi perusahaan atau organisasi, pengembangan karir ini akan membantu di dalam mengetahui dan memahami kemauan dan keinginan karyawan untuk berkembang lebih dan dapat disesuaikan dengan pertumbuhan dan perkembangan kondisi perusahaan.

PT Bank CIMB Niaga didirikan pada 26 September 1955 bergerak dalam bidang perbankan. CIMB Niaga merupakan bank yang pertamakali menawarkan kepada nasabahnyalayanan perbankan melalui mesin ATM (Automatic Teller Machine) di Indonesia. Pengembangan karir yang belum efektif di lingkungan Bank CIMB Niaga Cabang Pondok Indah berdasarkan observasi awal yang dilakukan, ditengarai menjadi akar permasalahan menurunnya kinerja karyawan khususnya pada divisi credit card. Penurunan kinerja karyawan dibuktikan dengan tidak tercapainya jumlah penjualan produk jika dibandingkan dengan target yang telah ditetapkan.

Pengembangan karir di lingkungan PT Bank 
CIMB Niaga Cabang Pondok Indah diharapkan akan menjadi jawaban dan solusi atas ancaman dan permasalahan yang muncul yang disebabkan oleh dinamika yang terjadi tidak hanya di lingkungan internal organisasi, tetapi juga lingkungan eksternal organisasi. Perkembangan teknologi di era 4.0 dengan kehadiran artificial intelegence yang digadang-gadang akan menjadi alternatif pengganti penggunaan tenaga manusia di masa yang akan datang, dan semakin tingginya tingkat persaingan antar bank menjadi permasalahan nyata yang dihadapi. Dinamika ini semakin diperparah dengan meningkatnya kejenuhan dalam bekerja dan ketidakpuasan bekerja yang memunculkan keinginan dari karyawan untuk meninggalkan organisasi atau perusahaan.

Kinerja karyawan merupakan suatu hal yang sangat penting di dalam mendukung usaha perusahaan untuk mencapai tujuannya. Salah satu cara yang dapat digunakan untuk melihat perkembangan perusahaan adalah dengan membandingkannya dengan hasil penilaian kinerja karyawan yang dimilikinya. Semakin tinggi kinerja yang ditunjukkan oleh karyawan secara langsung akan meningkatkan kinerja perusahaan. Kinerja sebagai kemajuan dan tingkat penyelesaian suatu pekerjaan baik kualitas maupun kuantitas yang harus meningkatkan standar hasil kerja karyawan dari waktu ke waktu atau hasil kerja yang dapat dicapai oleh sesorang atau sekelompol orang dalam rangka upaya mencapai tujuan organisasi bersangkutan secara legal dan sesuai dengan moral etika. Kinerja juga merupakan hasil dari usaha seseorang yang ingin dicapainya dengan adanya kemampuan dan perbuatan dalam situasi tertentu. Jadi bisa dikatakan prestasi kerja merupakan hasil keterkaitan antara usaha, kemampuan, dan persepsi tugas (Eddy Sutrisno, 2013).

\begin{tabular}{|c|c|c|c|}
\hline \multicolumn{4}{|c|}{ Tahun 2018} \\
\hline Bulan & $\begin{array}{c}\text { Target } \\
\text { Pencapaian }\end{array}$ & $\begin{array}{l}\text { Aktualisasi } \\
\text { Pencapaian }\end{array}$ & Selisih \\
\hline Januari & 400 & 344 & 56 \\
\hline Febuari & 400 & 316 & 84 \\
\hline Maret & 400 & 464 & 64 \\
\hline April & 400 & 990 & 590 \\
\hline Mei & 400 & 524 & 124 \\
\hline
\end{tabular}

\begin{tabular}{|l|c|c|c|}
\hline Juni & 400 & 386 & 14 \\
\hline Juli & 400 & 669 & 269 \\
\hline Agustus & 400 & 138 & 262 \\
\hline September & 400 & 532 & 132 \\
\hline Oktober & 400 & 974 & 574 \\
\hline November & 400 & 285 & 115 \\
\hline Desember & 400 & 423 & 23 \\
\hline & \multicolumn{4}{|c|}{ Sumber CIMB Niaga Cabang Pondok Indah 2018 } \\
\hline
\end{tabular}

Berdasarkan tabel 1 jelas terlihat bahwa terdapat fluktuasi pencapaian atas target penjualan yang ditetapkan oleh perusahaan yakni sebesar 400 aplikasi. Trisemester pertama pada 2018 diwarnai dengan tidak tercapainya target penjualan pada Januari (344 aplikasi) dan Februari (316). Namun sempat mencapai target pada Maret (464) dan di awal trisemester ke dua yakni pada April (990) dan Mei (524). Selanjutnya kembali tidak mencapat target di bulan Juni (386).

Pada awal trisemester ketiga yakni di bulan Juli terdapat peningkatan pencapaian sebesar (669), namun kembali tidak achieve pada Agustus (138). Pada September, dan awal tri semester ke empat diwarnai dengan pencapaian target secara berturut-turut yakni sebanyak (532) dan (974). Namun kembali tidak mencapai target di bulan November (285) dan kembali mencapai target di akhir tahun 2018 di bulan Desember (423). Rendahnya motivasi pekerja yang disebabkan adanya permasalahan dalam aktivitas pengembangan karir pekerja disinyalir menjadi penyebab turun-naiknya pencapaian pekerja terhadap target yang dibebankan oleh Perusahaan.

Berdasarkan latar belakang masalah di atas makapenulistertarikuntukmenelitipermasalahan mengenai: "Pengaruh Pengembangan Karir Terhadap Kinerja Karyawan Pada PT Bank CIMB Niaga Cabang Pondok Indah”.

\section{METODE}

Penelitian ini dilakukan dengan metode penelitian kuantitatif dan diolah dengan aplikasi statistik. Dilaksanakan di PT Bank CIMB Niaga Cabang Pondok Indah yang berlokasi di Jalan Raya Sultan Iskandar Muda No. 35F, Kelurahan Pondok Pinang, Kecamatan Kebayoran Lama, Jakarta Selatan. Penentuan sampel jenuh dilaksanakan kepada 40 responden dari keseluruhan populasi 
yakni seluruh karyawan di Divisi Kartu Kredit. Uji data yang dilaksanakan dalam penelitian ini adalah uji instrumen, uji korelasi, uji regresi linier sederhana, uji koefisien determiasi, dan uji hipotesis.

\section{HASIL DAN PEMBAHASAN}

Hasil

\section{Deskripsi Responden}

\section{Karakteristik Responden}

Responden dalam penelitian ini adalah 40 karyawan PT Bank CIMB Niaga Cabang Pondol Indah Divisi Kartu Kredit sebanyak 70 orang. Responden dibagi kedalam karakteristik berdasarkan berdasarkna jenis kelami, usia. dan tingkat pendidikan sbb;

\section{Berdasarkan Jenis Kelamin}

\begin{tabular}{c|l|c|c|c|c|}
\hline \multicolumn{6}{c|}{ Tabel 2. Karakteristik Responden Berdasarkan Jenis Kelamin } \\
\hline \multirow{3}{*}{ Valid } & Frequency & Percent & $\begin{array}{c}\text { Valid } \\
\text { Percent }\end{array}$ & $\begin{array}{c}\text { Cumulative } \\
\text { Percent }\end{array}$ \\
\cline { 3 - 6 } & Pria & 32 & 80,0 & 80,0 & 80,0 \\
\cline { 2 - 6 } & Wanita & 8 & 20,0 & 20,0 & 100,0 \\
\cline { 2 - 6 } & Total & 40 & 100,0 & 100,0 & \multicolumn{5}{c}{ Sumber : Data primer yang diolah, 2018 } \\
\hline \multicolumn{6}{|c|}{} \\
\hline
\end{tabular}

Tabel 2 menjelaskan bahwa rata-rata jenis kelamin responden yang memberikan data kepada penulis mayoritas rata-rata berjenis kelamin pria yaitu sebanyak 32 orang (80\%) dan berjenis kelamin wanita sebanyak 8 orang (20\%).

\section{Berdasarkan Usia Responden}

\begin{tabular}{|c|c|c|c|c|c|}
\hline \multicolumn{5}{|c|}{ Tabel 3. Responden Berdasarkan Usia } \\
\hline \multirow{3}{*}{ Valid } & Frequency & Percent & $\begin{array}{c}\text { Valid } \\
\text { Percent }\end{array}$ & $\begin{array}{c}\text { Cumulative } \\
\text { Percent }\end{array}$ \\
\cline { 2 - 6 } & $21-30$ tahun & 35 & 87,5 & 87,5 & 87,5 \\
\cline { 2 - 6 } & $31-40$ tahun & 5 & 12,5 & 12,5 & 100,0 \\
\cline { 2 - 6 } & Total & 52 & 100,0 & 100,0 & \multicolumn{5}{c|}{ Sumber : Data primer yang diolah, 2018 } \\
\hline \multicolumn{7}{|c|}{} & 52 & \multicolumn{5}{c}{} \\
\hline
\end{tabular}

Tabel 3 dapat menjelaskan bahwa rata-rata mayoritas responden yang memberikan data kepada penulis berusia 21-30 tahun yaitu sebanyak 35 orang $(87,5 \%)$, usia $31-40$ tahun yaitu sebanyak 5 orang $(12,5 \%)$.

\section{Berdasarkan Pendidikan Responden}

\begin{tabular}{|c|l|c|c|c|c|}
\hline \multicolumn{5}{|c|}{ Tabel 4. Responden Berdasarkan Pendidikan } \\
\hline \multirow{3}{*}{ Valid } & Frequency & Percent & $\begin{array}{c}\text { Valid } \\
\text { Percent }\end{array}$ & $\begin{array}{c}\text { Cumulative } \\
\text { Percent }\end{array}$ \\
\cline { 2 - 6 } & $\begin{array}{l}\text { SMA/ } \\
\text { Sederajat }\end{array}$ & 37 & 92,5 & 92,5 & 92,5 \\
\cline { 2 - 6 } & Sarjana & 3 & 7,5 & 7,5 & 100,0 \\
\cline { 2 - 6 } & Total & 40 & 100,0 & 100,0 & \multicolumn{5}{|c|}{ Sumber : Data primer yang diolah, 2018 } \\
\hline
\end{tabular}

Tabel4menjelaskan bahwarata-rata mayoritas responden yang memberikan data kepada penulis berpendidikan terakhir sarjana yaitu sebanyak 3 orang $(7,5 \%)$, yang berpendidikan terakhir SMA sebanyak 37 orang $(92,5 \%)$.

\section{Uji Validitas}

\begin{tabular}{|c|c|c|c|c|}
\hline \multicolumn{5}{|c|}{ Tabel 5. Uji Validitas Pernyataan Variabel Pengembangan Karir (X) } \\
\hline No & Pernyataan & $\mathbf{r}_{\text {hitung }}$ & $\begin{array}{c}r_{\text {tabel }}(n-2) \\
40-2=38\end{array}$ & $\begin{array}{c}\text { Keputusan } \\
\text { Validitas } \\
r_{\text {hitung }}>r_{\text {tabel }}\end{array}$ \\
\hline I & Sikap atasan, Rekanan c & Jawahan & & \\
\hline 1 & $\begin{array}{l}\text { Atasan saya selalu } \\
\text { memberikan dukungan } \\
\text { dalam hal pekerjaan }\end{array}$ & 0,4063 & 0,3120 & Valid \\
\hline 2 & $\begin{array}{l}\text { Dalam bekerja saya } \\
\text { selalu bersikap sopan } \\
\text { terhadap semua } \\
\text { karyawan }\end{array}$ & 0,4489 & 0,3120 & Valid \\
\hline II & Pengalaman & & & \\
\hline 3 & $\begin{array}{l}\text { Saya mengutamakan } \\
\text { Pengalaman dalam } \\
\text { setiap menyelesaikan } \\
\text { pekerjaan untuk } \\
\text { meningkatkan hasil } \\
\text { kerja }\end{array}$ & 0,5981 & 0,3120 & Valid \\
\hline 4 & $\begin{array}{l}\text { Selama bekerja } \\
\text { saya cukup banyak } \\
\text { mendapatkan } \\
\text { pengalaman yang } \\
\text { menarik }\end{array}$ & 0,3895 & 0,3120 & Valid \\
\hline III & Pendidikan & & & \\
\hline 5 & $\begin{array}{l}\text { Pendidikan yang } \\
\text { saya peroleh mampu } \\
\text { mengembangkan karir } \\
\text { saya }\end{array}$ & 0,5346 & 0,3120 & Valid \\
\hline 6 & $\begin{array}{l}\text { Dengan Pendidikan, } \\
\text { saya memiliki } \\
\text { wawasaan yang luas } \\
\text { terhadap pekerjaan } \\
\text { saya }\end{array}$ & 0,3482 & 0,3120 & Valid \\
\hline IV & Prestasi & & & \\
\hline 7 & $\begin{array}{l}\text { Setiap karyawan } \\
\text { yang berprestasi } \\
\text { mendapatkan } \\
\text { kesempatan yang } \\
\text { sama dalam setiap } \\
\text { promosi }\end{array}$ & 0,3646 & 0,3120 & Valid \\
\hline 8 & $\begin{array}{l}\text { Saya mengetahui } \\
\text { bagaimana } \\
\text { melaksanakan } \\
\text { pekerjaan yang efektif } \\
\text { dan efisien }\end{array}$ & 0,3885 & 0,3120 & Valid \\
\hline
\end{tabular}




\begin{tabular}{|c|l|c|c|c|}
\hline IV & Nasib & Valid \\
\hline 9 & $\begin{array}{l}\text { Jika saya bekerja } \\
\text { sungguh-sungguh } \\
\text { maka nasib saya akan } \\
\text { semakin baik }\end{array}$ & 0,3609 & 0,3120 & Valid \\
\hline 10 & $\begin{array}{l}\text { Saya puas dengan } \\
\text { sistem promosi yang } \\
\text { ada diperusahaan saya } \\
\text { agar nasib saya dapat } \\
\text { berubah }\end{array}$ & 0,3826 & 0,3120 & \multicolumn{3}{|c|}{ Sumber data: Output SPSS yang diolah, 2018 } \\
\hline \multicolumn{4}{|c|}{}
\end{tabular}

Berdasarkan hasil uji validitas instrumen didapatlah hasil dari variabel independen (kinerja karyawan) yaitu bahwa semua data valid. Untuk menentukan validitas ini dengan ketentuan jika $\mathrm{r}_{\text {hitung }}>\mathrm{r}_{\text {tabel }}$ maka instrument (item) tersebut dapat dinyatakan valid.

\begin{tabular}{|c|c|c|c|c|}
\hline \multirow[b]{2}{*}{ No } & \multirow[b]{2}{*}{ Pernyataan } & \multicolumn{3}{|c|}{ Uji Validitas } \\
\hline & & $\mathbf{r}_{\text {hitung }}$ & $\begin{array}{l}r_{\text {tabel }}(n-2) \\
40-2=38\end{array}$ & $\begin{array}{c}\text { Keputusan } \\
\text { Validitas } \\
r_{\text {hitung }}>r_{\text {tabel }}\end{array}$ \\
\hline 1 & \multicolumn{4}{|l|}{ Kejujuran } \\
\hline 1 & $\begin{array}{l}\text { Dalam bekerja saya } \\
\text { selalu memiliki } \\
\text { kejujuran terhadap } \\
\text { diri sendiri, teman dan } \\
\text { pimpinan }\end{array}$ & 0,4342 & 0,3120 & Valid \\
\hline 2 & $\begin{array}{l}\text { Saya mengutamakan } \\
\text { kejujuran dalam } \\
\text { setiap menyelesaikan } \\
\text { pekerjaan untuk } \\
\text { meningkatkan hasil } \\
\text { kerja }\end{array}$ & 0,6081 & 0,3120 & Valid \\
\hline II & \multicolumn{4}{|l|}{ Tanggung Jawab } \\
\hline 3 & $\begin{array}{l}\text { Saya mampu } \\
\text { menyelesaikan tugas } \\
\text { yang diberikan secara } \\
\text { konsisten }\end{array}$ & 0,6454 & 0,3120 & Valid \\
\hline 4 & $\begin{array}{l}\text { Saya mampu } \\
\text { mempertanggung } \\
\text { jawabkan pekerjaan } \\
\text { saya kepada atasan } \\
\text { dan teman kerja }\end{array}$ & 0,3529 & 0,3120 & Valid \\
\hline III & \multicolumn{4}{|l|}{ Kerja Sama } \\
\hline 5 & $\begin{array}{l}\text { Saya lebih } \\
\text { mementingkan } \\
\text { kepentingan Bersama }\end{array}$ & 0,3415 & 0,3120 & Valid \\
\hline 6 & $\begin{array}{l}\text { Saya mampu bekerja } \\
\text { sama dengan siapapun }\end{array}$ & 0,4072 & 0,3120 & Valid \\
\hline IV & \multicolumn{4}{|l|}{ Kehadiran } \\
\hline 7 & $\begin{array}{l}\text { Saya merasa bahwa } \\
\text { selalu menggunakan } \\
\text { waktu dengan efesien }\end{array}$ & 0,5106 & 0,3120 & Valid \\
\hline 8 & $\begin{array}{l}\text { Dalam bekerja saya } \\
\text { selalu datang lebih } \\
\text { awal }\end{array}$ & 0,5699 & 0,3120 & Valid \\
\hline IV & \multicolumn{4}{|l|}{ Kedisiplinan } \\
\hline 9 & $\begin{array}{l}\text { Dalam bekerja saya } \\
\text { memiliki kedisiplinan } \\
\text { yang baik }\end{array}$ & 0,6256 & 0,3120 & Valid \\
\hline 10 & $\begin{array}{l}\text { Tempat saya bekerja } \\
\text { kedisplinan sangat } \\
\text { diperhatikan }\end{array}$ & 0,5397 & 0,3120 & Valid \\
\hline \multicolumn{5}{|c|}{ Sumber data: Output SPSS yang diolah, 2018} \\
\hline
\end{tabular}

Berdasarkan hasil uji validitas instrumen didapatlah hasil dari variabel independen (kinerja karyawan) yaitu bahwa semua data valid. Untuk menentukan validitas ini dengan ketentuan jika $\mathrm{r}_{\text {hitung }}>\mathrm{r}_{\text {tabel }}$ maka instrument (item) tersebut dapat dinyatakan valid.

\section{Uji Reliabilitas}

\section{Uji Reliabilitas Variabel Pengembangan Karir (X)}

Setelah mengetahui hasil validitas instrumen seperti yang tertera di atas, maka peneliti selanjutnya melakukan uji reliablitas instrumen untuk mengetahui ketepatan, keakuratan, dan ketelitian yang ditunjukkan oleh instrumen pengukuran. Hasil pengukuran dapat dikatakan reliable jika $\mathrm{r}_{\text {cronbach }}>\mathrm{r}_{\text {tabel }}$

Menghitung varians skor setiap butir pernyataan dengan rumus:

Perhitungan varians butir pernyataan selanjutnya dapat dihitung dengan cara yang sama.

Menghitung jumlah varians skor butir pernyataan:

$$
\begin{aligned}
\sum s \mathrm{si}= & \mathrm{si}^{2} 1+\mathrm{si}^{2} 2+\mathrm{si}^{2} 3+\ldots . .+\mathrm{si}^{2} \mathrm{n} \\
\Sigma \mathrm{si}= & 0,3494+0,4244+0,5244+0,34+ \\
& 0,2444+0,3994+0,4375+0,36+0,24 \\
& +0,1744=\mathbf{3 , 4 9 3 8}
\end{aligned}
$$

Menghitung varians total semua butir pernyataan.

Setelah melakukan uji reliabilitas tiap-tiap butir varians, maka selanjutnya dilakukan pencarian varians total skor variabel Pengembangan Karir (X). 


$$
S i^{2}=\frac{\sum x t^{2}-\frac{\left(\sum t\right)^{2}}{n}}{n}
$$

Diketahui :

$\sum \mathrm{xt}=1.724$

$\sum \mathrm{xt}^{2}=74.552$

$\mathrm{n}=40$

$S i^{2}=\frac{74.552-\frac{(1.724)^{2}}{40}}{40}$

$S i^{2}=\frac{74.552-\frac{2.972 .174}{40}}{40}$

$S i^{2}=\frac{74.552-74.304}{40}$

$S i^{2}=\frac{248}{40}$

$S \mathbf{t}^{2}=6,1900$

Menghitung nilai koefisien reliabilitas variable Pengembangan Karir :

Setelah mendapatkan hasil penjumlahan tiap varians skor Pengembangnan Karir dan mendapatkan hasil total varians skor Pengembangan Karir, maka selanjutnya dilakukan uji relabilitas untuk variabel Pengembangan Karir. Dari data varians skor dan total varians skor variabel Pengembangan Karir (X) diketahui:

$$
\begin{aligned}
& \mathrm{K}=10 \text { (Banyaknya Butir Pernyataan) } \\
& \sum \mathrm{S}^{2} \quad=3.4938 \\
& \mathrm{St}^{2} \quad=6,1900 \\
& r^{11}=\frac{K}{K-1} \quad 1-\frac{\sum S^{2}}{S t^{2}} \\
& r^{11}=\frac{10}{10-1} \quad 1-\frac{3,4938}{6,1900} \\
& r^{11}=\frac{10}{9} \\
& r_{11}=(1,1111) \\
& r^{11}=0,4840 \\
& 1-0,5644
\end{aligned}
$$

Dengan demikian, karena hasil perhitungan $\mathrm{r}^{11}$ lebih besar dari pada $\mathrm{r}_{\text {table }}(0,4840>0,3120)$ hal tersebut menunjukkan bahwa instrumen penelitian variabel Pengembangan Karir dapat dinyatakan reliable atau dapat dipercaya.

\section{Uji Reliabilitas Kinerja Karyawan(Y)}

Setelah mengetahui hasil validitas instrumen seperti yang tertera di atas, maka peneliti selanjutnya melakukan uji reliablitas instrumen untuk mengetahui ketepatan, keakuratan, dan ketelitian yang ditunjukkan oleh instrumen pengukuran. Hasil pengukuran dapat dkatakan reliable jika $\mathrm{r}_{\text {cronbach }}>\mathrm{r}_{\text {tabel }}$

Menghitung varians skor setiap butir per- nyataan dengan rumus:

$$
S i^{2}=\frac{\sum x i^{2}-\frac{\left(\sum x\right)^{2}}{n}}{n}
$$

Perhitungan Varians Butir Pernyataan No 1

$\sum x i=172$

$\sum \mathrm{xi}^{2}=752$

$\mathrm{n}=40$

jawab :

$$
\begin{aligned}
& S i^{2}=\frac{752-\frac{(172)^{2}}{40}}{40} \\
& S i^{2}=\frac{752-\frac{29.584}{40}}{40} \\
& S i^{2}=\frac{752-740}{40} \\
& S i^{2}=\frac{12}{52} \\
& \mathbf{S i}^{2}=\mathbf{0 , 3 1 0 0}
\end{aligned}
$$

Perhitungan varians butir pernyataan selanjutnya dapat dihitung dengan cara yang sama.

Menghitung jumlah varians skor butir pernyataan:

$$
\begin{aligned}
\Sigma s i= & \mathrm{si}^{2} 1+\mathrm{si}^{2} 2+\mathrm{si}^{2} 3+\ldots . .+\mathrm{si}^{2} \mathrm{n} \\
\Sigma \mathrm{si}= & 0,3100+0,4744+0,4375+0,4275+ \\
& 0,2600+0,4344+0,2994+0,4475+ \\
& 0,2275+0,1944=\mathbf{3 , 5 1 2 5}
\end{aligned}
$$

Menghitung varians total semua butir pernyataan.

Setelah melakukan uji reliabilitas tiap-tiap butir varians, maka selanjutnya dilakukan pencarian varians total skor variabel kinerja karyawan.

$$
\begin{aligned}
& S i^{2}=\frac{\sum x t^{2}-\frac{\left(\sum t\right)^{2}}{n}}{n} \\
& \text { Diketahui: } \\
& \sum \mathrm{xt}=1.738 \\
& \sum \mathrm{xt}^{2}=75.866 \\
& \mathrm{n}=40 \\
& S i^{2}=\frac{75.866-\frac{(1.738)^{2}}{40}}{40} \\
& S i^{2}=\frac{75.866-\frac{3.020 .644}{40}}{40} \\
& S i^{2}=\frac{75.866-75.516}{40} \\
& S i^{2}=\frac{350}{40} \\
& \mathbf{S t}^{2}
\end{aligned}
$$

Menghitung nilai koefisien reliabilitas variabel kinerja karyawan:

Setelah mendapatkan hasil penjumlahan tiap varians skor kinerja karyawan dan mendapatkan hasil total varians skor kinerja karyawan, maka 
selanjutnya dilakukan uji relabilitas untuk variabel kinerja karyawan. Dari data varians skor dan total varians skor variabel kinerja karyawan diketahui:

$$
\begin{array}{lcc}
\mathrm{K} & =10 \text { (Banyaknya Butir Pernyataan) } \\
\begin{array}{ll}
\sum \mathrm{S}^{2} & =3,5125 \\
\mathrm{St}^{2} & =8.7475
\end{array} & \\
r^{11}=\frac{K}{K-1} & 1-\frac{\sum S^{2}}{S t^{2}} \\
r^{11}=\frac{10}{10-1} & 1-\frac{3,5125}{8,7475} \\
r^{11}=\frac{10}{9} & 1-0,4015 \\
r_{11}=(1,1111) & (0,5985) \\
r^{11}=\mathbf{0 , 6 6 5 0} &
\end{array}
$$

\begin{tabular}{|c|c|c|c|c|c|c|c|}
\hline \multirow{2}{*}{ No } & \multirow{2}{*}{ Pernyataan } & SS & $S$ & CS & TS & STS & \multirow{2}{*}{ TOTAL } \\
\hline & & 5 & 4 & 3 & 2 & 1 & \\
\hline 1 & \multicolumn{7}{|c|}{ Sikap atasan, Rekanan dan bawahan } \\
\hline 1 & $\begin{array}{l}\text { Atasan saya selalu } \\
\text { memberikan dukungan } \\
\text { dalam hal pekerjaan }\end{array}$ & 14 & 23 & 3 & 0 & 0 & 40 \\
\hline 2 & $\begin{array}{l}\text { Dalam bekerja saya selalu } \\
\text { bersikap sopan terhadap } \\
\text { semua karyawan }\end{array}$ & 7 & 26 & 6 & 1 & 0 & 40 \\
\hline$\|$ & \multicolumn{7}{|l|}{ Pengalaman } \\
\hline 3 & $\begin{array}{l}\text { Saya mengutamakan } \\
\text { Pengalaman dalam setiap } \\
\text { menyelesaikan pekerjaan } \\
\text { untuk meningkatkan hasil } \\
\text { kerja }\end{array}$ & 16 & 17 & 7 & 0 & 0 & 40 \\
\hline 4 & $\begin{array}{l}\text { Selama bekerja saya cukup } \\
\text { banyak mendapatkan } \\
\text { pengalaman yang menarik }\end{array}$ & 8 & 29 & 2 & 1 & 0 & 40 \\
\hline III & \multicolumn{7}{|l|}{ Pendidikan } \\
\hline 5 & $\begin{array}{l}\text { Pendidikan yang } \\
\text { saya peroleh mampu } \\
\text { mengembangkan karir saya }\end{array}$ & 9 & 29 & 2 & 0 & 0 & 40 \\
\hline 6 & $\begin{array}{l}\text { Dengan Pendidikan, saya } \\
\text { memiliki wawasaan yang } \\
\text { luas terhadap pekerjaan } \\
\text { saya }\end{array}$ & 24 & 13 & 3 & 0 & 0 & 40 \\
\hline IV & \multicolumn{7}{|l|}{ Prestasi } \\
\hline 7 & $\begin{array}{l}\text { Setiap karyawan yang } \\
\text { berprestasi mendapatkan } \\
\text { kesempatan yang sama } \\
\text { dalam setiap promosi }\end{array}$ & 15 & 20 & 5 & 0 & 0 & 40 \\
\hline 8 & $\begin{array}{l}\text { Saya mengetahui } \\
\text { bagaimana melaksanakan } \\
\text { pekerjaan yang efektif dan } \\
\text { efisien }\end{array}$ & 12 & 24 & 4 & 0 & 0 & 40 \\
\hline
\end{tabular}

Dengan demikian, karena hasil perhitungan

\begin{tabular}{|c|c|c|c|c|c|c|c|}
\hline IV & Nasib & & & & & & \\
\hline 9 & $\begin{array}{l}\text { Jika saya bekerja sungguh- } \\
\text { sungguh maka nasib saya } \\
\text { akan semakin baik }\end{array}$ & 24 & 16 & 0 & 0 & 0 & 40 \\
\hline 10 & $\begin{array}{l}\text { Saya puas dengan } \\
\text { system promosi yang ada } \\
\text { diperusahaan saya agar } \\
\text { nasib saya dapat berubah }\end{array}$ & 31 & 9 & 0 & 0 & 0 & 40 \\
\hline & TOTAL & 127 & 164 & 27 & 2 & 0 & 320 \\
\hline & PERSENTASE & $39,69 \%$ & $51,25 \%$ & $8,44 \%$ & $0,63 \%$ & $0,00 \%$ & $100 \%$ \\
\hline
\end{tabular}
$\mathrm{r}^{11}$ lebih besar dari pada $\mathrm{r}_{\text {table }}(0,6650>0,3120)$ hal tersebut menunjukkan bahwa instrumen penelitian variable kinerja karyawan dapat dinyatakan reliable atau dapat dipercaya.

\section{Pembahasan}

\section{Variabel Pengembangan Karir (X)}

Seluruh jawaban yang diperoleh dari pernyataan variabel Pengembangan Karir diambil dengan menjumlahkan skor lalu dibagi 320 (jumlah jawaban) jumlah hasil jawaban dan dikalikan $100 \%$. Jumlah hasil jawaban kuesioner adalah $=127+164+27+2+0=320$, di mana jika dipresentasikan akan menjadi sebagai berikut:

$$
\begin{aligned}
& \mathrm{SS}=\frac{127 \times 100 \%=39,69 \%}{320}=51,25 \% \\
& \mathrm{~S}=\frac{164 \times 100 \%}{320}=8,44 \% \\
& \mathrm{CS}=\frac{27 \times 100 \%}{320}=0,63 \% \\
& \mathrm{TS}=\frac{2 \times 100 \%}{320}=0 \% \\
& \mathrm{STS}=\frac{0 \times 100 \%}{320}=0
\end{aligned}
$$

Angket kuesioner Pengembangan Karir pada PT Bank CIMB Niaga Cabang Pondok Indah ini mendapat respon sangat baik. Peneliti menyimpulkan berdasarkan hasil jawaban seluruh responden atau karyawan yang berjumlah 40 orang dengan 10 pernyataan, yang menjawab "Sangat Setuju" sebanyak 127 atau 39,69\%, jawaban "Setuju" sebanyak 164 atau 51,25\%, jawaban "Cukup Setuju” sebanyak 27 atau 8,44\%, jawaban “Tidak Setuju” sebanyak 2 atau 0,63\%, sedangkan jawaban "Sangat Tidak Setuju" sebanyak 0 atau $0 \%$. 


\section{Variabel Kinerja Karyawan (Y)}

\begin{tabular}{|c|c|c|c|c|c|c|c|}
\hline \multicolumn{8}{|c|}{ Tabel 8. Distribusi Jawaban Kuesioner Variabel Kinerja Karyawan (Y) } \\
\hline \multirow{2}{*}{ No } & \multirow{2}{*}{ Pernyataan } & SS & s & cS & TS & STS & \multirow{2}{*}{ TOTAL } \\
\hline & & 5 & 4 & 3 & 2 & 1 & \\
\hline I & \multicolumn{7}{|l|}{ Kejujuran } \\
\hline 1 & $\begin{array}{l}\text { Dalam bekerja saya selalu } \\
\text { memiliki kejujuran terhadap } \\
\text { diri sendiri, teman dan } \\
\text { pimpinan }\end{array}$ & 14 & 24 & 2 & 0 & 0 & 40 \\
\hline 2 & $\begin{array}{l}\text { Saya mengutamakan } \\
\text { kejujuran dalam setiap } \\
\text { menyelesaikan pekerjaan } \\
\text { untuk meningkatkan hasil } \\
\text { kerja }\end{array}$ & 8 & 27 & 3 & 2 & 0 & 40 \\
\hline$\|$ & \multicolumn{7}{|l|}{ Tanggung Jawab } \\
\hline 3 & $\begin{array}{l}\text { Saya mampu menyelesaikan } \\
\text { tugas yang diberikan secara } \\
\text { konsisten }\end{array}$ & 15 & 20 & 5 & 0 & 0 & 40 \\
\hline 4 & $\begin{array}{l}\text { Saya mampu } \\
\text { mempertanggung jawabkan } \\
\text { pekerjaan saya kepada } \\
\text { atasan dan teman kerja }\end{array}$ & 11 & 25 & 3 & 1 & 0 & 40 \\
\hline III & \multicolumn{7}{|l|}{ Kerja Sama } \\
\hline 5 & $\begin{array}{l}\text { Saya lebih mementingkan } \\
\text { kepentingan Bersama }\end{array}$ & 13 & 26 & 1 & 0 & 0 & 40 \\
\hline 6 & $\begin{array}{l}\text { Saya mampu bekerja sama } \\
\text { dengan siapapun }\end{array}$ & 29 & 7 & 4 & 0 & 0 & 40 \\
\hline IV & \multicolumn{7}{|l|}{ Kehadiran } \\
\hline 7 & $\begin{array}{l}\text { Saya merasa bahwa selalu } \\
\text { menggunakan waktu } \\
\text { dengan efesien }\end{array}$ & 13 & 25 & 2 & 0 & 0 & 40 \\
\hline 8 & $\begin{array}{l}\text { Dalam bekerja saya selalu } \\
\text { datang lebih awal }\end{array}$ & 9 & 25 & 5 & 1 & 0 & 40 \\
\hline IV & \multicolumn{7}{|l|}{ Kedisipliman } \\
\hline 9 & $\begin{array}{l}\text { Dalam bekerja saya } \\
\text { memiliki kedisiplinan } \\
\text { yang baik }\end{array}$ & 26 & 14 & 0 & 0 & 0 & 40 \\
\hline 10 & $\begin{array}{l}\text { Tempat saya bekerja } \\
\text { kedisplinan sangat } \\
\text { diperhatikan }\end{array}$ & 34 & 5 & 1 & 0 & 0 & 40 \\
\hline & TOTAL & 130 & 165 & 21 & 4 & 0 & 320 \\
\hline & PERSENTASE & $40,63 \%$ & $51,56 \%$ & $6,56 \%$ & $1,25 \%$ & $0 \%$ & $100 \%$ \\
\hline \multicolumn{8}{|c|}{ Sumber : Data primer yang diolah, 2018.} \\
\hline
\end{tabular}

Seluruh jawaban yang diperoleh dari pernyataan variabel kinerja karyawan diambil dengan menjumlahkan skor lalu dibagi 320 (jumlah jawaban) jumlah hasil jawaban dan dikalikan $100 \%$. Jumlah hasil jawaban kuesioner adalah $=130+165$ $+21+4+0=320$, di mana jika dipresentasikan akan menjadi sebagai berikut :

$$
\begin{aligned}
& \mathrm{SS}=\frac{130 \times 100 \%}{320}=40,63 \% \\
& \mathrm{~S}=\frac{165 \times 100 \%}{320}=51,56 \% \\
& \mathrm{CS}=\frac{21 \times 100 \%}{320}=6,56 \%
\end{aligned}
$$

$$
\begin{aligned}
& \mathrm{TS}=\frac{4 \times 100 \%=1.25 \%}{320}=0 \% \\
& \mathrm{STS}=\frac{0 \times 100 \%}{320}=0 \%
\end{aligned}
$$

Angket kuesioner kinerja karyawan pada PT Bank CIMB Niaga Cabang Pondok Indah ini mendapat respon sangat baik. Peneliti menyimpulkan berdasarkan hasil jawaban seluruh responden atau karyawan yang berjumlah 40 orang dengan 10 pernyataan, yang menjawab "Sangat Setuju" sebanyak 130 atau 40,63\%, jawaban "Setuju" sebanyak 165 atau 51,56\%, jawaban "Cukup Setuju” sebanyak 21 atau 6,56\%, jawaban "Tidak Setuju” sebanyak 4 atau 1,25\%, sedangkan jawaban "Sangat Tidak Setuju" sebanyak 0 atau $0 \%$.

\section{Persamaan Regresi Linier Sederhana}

Analisis regresi adalah salah satu alat analisis yang digunakan untuk membuat suatu persamaan yang menghubungkan antara variabel independent $(\mathrm{X})$ dan variabel dependent $(\mathrm{Y})$ dan sekaligus untuk menentukan nilai ramalan atau dugaan, menurut Sugiyono (2011:270). Regresi linier sederhana didasarkan pada hubungan fungsional ataupun kausal satu varabel independen dengan atau variabel dependen. Persamaan umum regresi linier sederhana dalam penelitian ini dinyatakan dengan rumus regresi linier sederhana sebagai berikut :

$$
\mathbf{Y}=\mathbf{a}+\mathbf{b x}
$$

Dalam rumus regresi tersebut, peneliti terlebih dahulu mencari nilai a dan b dengan menggunakan rumus sebagai berikut :

Diketahui :

$$
\begin{aligned}
\mathrm{n}=40 & \\
\sum \mathrm{x} & =1.724 \\
\sum \mathrm{y} & =1.738 \\
\sum \mathrm{x}^{2} & =74.552 \\
\sum \mathrm{y}^{2} & =75.866 \\
\sum \mathrm{xy} & =74.981
\end{aligned}
$$

Di mana b = Koefisien Regresi, dengan menggunakan rumus: 


$$
\begin{aligned}
b & =\frac{n\left(\sum x y\right)-\left(\sum x\right)\left(\sum y\right)}{n\left(\sum \mathrm{x}^{2}\right)-\left(\sum \mathrm{x}\right)^{2}} \\
b & =\frac{40(74.981)-(1.724)(1.738)}{40(74.552)-(1.724)^{2}} \\
b & =\frac{2.999 .240-2.996 .312}{2.982 .080-2.972 .176} \\
b & =\frac{2.928}{9.904} \\
b & =0,29
\end{aligned}
$$

Dari perhitungan di atas, maka dketahui nilai untuk b adalah 0,2956, di mana $\mathrm{a}=$ Konstanta, dengan menggunakan rumus :

$$
\begin{aligned}
& a=\frac{\sum \mathrm{y}}{n}+\frac{\mathrm{b}\left(\sum \mathrm{x}\right)}{n} \\
& a=\frac{1.738}{40}+\frac{0,2956(1.724)}{40} \\
& a=43,4500+12,7420 \\
& a=56,19
\end{aligned}
$$

Maka diperoleh persamaan regresi linier sederhana sebagai berikut :

$$
\begin{aligned}
& \mathrm{Y}=\mathrm{a}+\mathrm{bx} \\
& \mathrm{Y}=56,19+0,29 \mathrm{X}
\end{aligned}
$$

Adapun interpretasi dari persamaan regresi linier sederhana tersebut adalah :

$\mathrm{a}=56,19$ menyatakan bahwa jika $\mathrm{X}$ tetap (tidak mengalami perubahan) maka nilai konstanta Y adalah sebesar 0,29.

$\mathrm{b}=0,29$ menyatakan bahwa jika $\mathrm{X}$ bertambah, maka Y akan mengalami peningkatan sebesar 0,29.

\section{Uji Koefiisen Korelasi}

Koefisien korelasi adalah angka yang menunjukkan kuat atau lemahnya pengaruh antara dua variabel. Besarnya koefisien korelasi (r) antara dua variabel adalah untuk dapat memberi interpretasi terhadap kuat atau lemahnya pengaruh maka digunakan pedoman menurut Sugiyono (2015:231) sebagai berikut :

\begin{tabular}{|c|c|}
\hline \multicolumn{2}{|c|}{ Tabel 9. Pedoman untuk Memberikan Interprestasi Koefisien Korelasi } \\
\hline Interval Koefisien & Tingkat Hubungan \\
\hline $0,00-0,199$ & Sangat Lemah \\
\hline $0,20-0,399$ & Lemah \\
\hline $0,40-0,599$ & Cukup Kuat \\
\hline $0,60-0,799$ & Kuat \\
\hline $0,80-1,000$ & Sangat Kuat \\
\hline
\end{tabular}

Data yang digunakan untuk menghitung koefisien korelasi dapat dilihat pada tabel di bawah ini:

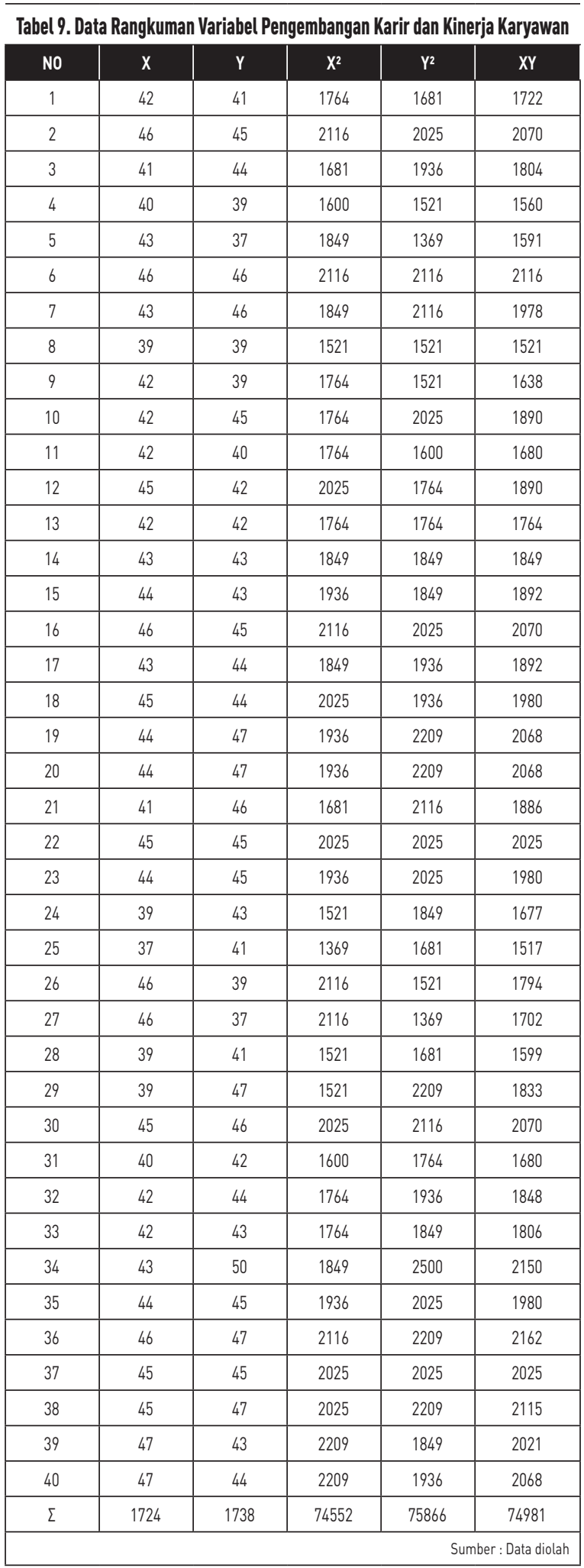

Berikut ini adalah perhitungan korelasi derajat hubungan antara variabel Pengembangan Karir dengan variabel kinerja dengan rumus produc moment yaitu : 


$$
\begin{aligned}
\mathrm{n}= & 40 \text { (Jumlah responden) } \\
\Sigma \mathrm{x}= & 1.724 \text { (Skor total pernyataan variabel } \\
& \text { Pengembangan Karir) } \\
\Sigma \mathrm{y}= & 1.738 \text { (Skor total pernyataan variabel } \\
& \text { kinerja karyawan) } \\
\sum \mathrm{x}^{2}= & 74.552 \\
\sum \mathrm{y}^{2}= & 75.866 \\
\sum \mathrm{xy}= & 74.981 \\
r= & \frac{n\left(\sum x y\right)-\left(\sum x\right)\left(\sum y\right)}{\sqrt{\left\{n \cdot \sum x^{2}-\left(\sum x\right)^{2}\right\}\left\{n \cdot \sum y^{2}-\left(\sum y\right)^{2}\right\}}} \\
r= & \frac{40(74.981)-(1.724)(1.738)}{\sqrt{\left\{40.74 .552-(1.724)^{2}\right\}}\left\{40.75 .866-(1.738)^{2}\right\}} \\
r= & \frac{2.999 .240-2.996 .312}{\sqrt{\{2.982 .080-2.972 .176\}}\{3.034 .640-3.020 .644\}} \\
r= & \frac{2.928}{\sqrt{\{9.904\}}\{13.996\}} \\
r= & \frac{2.928}{11.774} \\
r= & 0,2487
\end{aligned}
$$

Berdasarkan hasil analisis di atas dengan menggunakan korelasi Pearson Product Moment didapat nilai $r$ sebesar 0,2487 . Sesuai dengan pedoman interprestasi koefisien korelasi hal ini menunjukkan bahwa nilai korelasi antara pengembangan karir dan kinerja karyawan sebesar 0,2487 yang artinya terdapat pengaruh positif atau tingkat hubungan yang "Lemah" antara pengembangan karir terhadap kinerja karyawan pada PT Bank CIMB Niaga cabang Pondok Indah.

\section{Koefisien Determinasi}

Untuk mengetahui seberapa besar pengaruh koefisien determinasi antara variabel $\mathrm{X}$ dan variabel $\mathrm{Y}$, maka digunakan rumus:

Diketahui :

$\mathrm{Rxy}=0,0618$

Untuk rumus analisis koefisien determinasi adalah:

$$
\begin{aligned}
& \mathrm{KD}=(\mathrm{rxy})^{2} \times 100 \% \\
& \mathrm{KD}=(0,2487)^{2} \times 100 \% \\
& \mathrm{KD}=0,0618 \times 100 \% \\
& \mathrm{KD}=6,18 \%
\end{aligned}
$$

Koefisien Determinasi pengembangan karir terhadap Kinerja sebesar 6,18\%, sedangkan sisanya 93,82\% PT Bank CIMB Niaga Cabang Pondok Indah dipengaruhi oleh faktor-faktor lain yang tidak peneliti masukkan sebagai indikator dalam penelitian ini. Hal ini sekaligus membuktikan fakta berbeda mengenai succession plan terutama pengembangan karir yang menjadi salah satu issue penting bagi organisasi dan institusi yang lain, tetapi tidak di PT Bank CIMB Niaga Cabang Pondok Indah.

\section{Uji Signifkansi Koefisien Korelasi}

Untuk mengetahui apakah Pengembangan Karir benar-benar mempengaruhi kinerja karyawan, perlu dilakukan uji signifikasi korelasi dengan menentukan uji thitung sebagai berikut:

Merumuskan Hipotesis:

- $\mathrm{H}_{0}: \mathrm{rxy}=0$ “Tidak terdapat pengaruh yang signifikan pengembangan karir terhadap kinerja karyawan pada PT Bank CIMB Niaga Cabang Pondok Indah".

- $\mathrm{H}_{1}$ : rxy $>0$ "Terdapat pengaruh yang signifikan pengembangan karir terhadap kinerja karyawan pada PT Bank CIMB Niaga Cabang Pondok Indah".

- Uji Signifikan

Diketahui :

$\mathrm{rxy}=0,0618$

$\mathrm{t}_{\text {table }}(\alpha=5 \%, \mathrm{df}=\mathrm{n}-2)=2,0262$

untuk rumus uji signifikan adalah :

$$
\begin{aligned}
\text { tHitung } & =\frac{\operatorname{rxy} \sqrt{\mathrm{n}-2}}{\sqrt{1-\mathrm{rxy}^{2}}} \\
\text { tHitung } & =\frac{0,0618 \sqrt{40-2}}{\sqrt{1-(0,0618)^{2}}} \\
\text { tHitung }= & \frac{0,0618 \sqrt{38}}{\sqrt{1-0,0038}} \\
\text { tHitung }= & \frac{0,0618(6,1644)}{0,9981} \\
\text { tHitung }= & \frac{0,3813}{0,9981} \\
\text { tHitung }= & 0,3820 \\
& \mathbf{( 0 , 3 8 2 0 < \mathbf { 2 , 0 2 6 2 } )}
\end{aligned}
$$

Dengan demikian, karena $\mathrm{t}_{\text {hitung }}$ lebih kecil dari $_{\text {table }}(0,3820<2,0262)$, maka hal tersebut menunjukkan bahwa tidak terdapat pengaruh yang signifikan, maka $\mathrm{H}_{0}$ diterima dan $\mathrm{H}_{1}$ ditolak. Ini artinya bahwa variabel Pengembangan Karir tidak memiliki pengaruh yang signifikan terhadap Kinerja Karyawan pada PT Bank CIMB Niaga 
Cabang Pondok Indah.

\section{SIMPULAN}

Dari hasil penelitian yang telah dilakukan pada karyawan PT Bank CIMB Niaga Cabang Pondok Indah, maka penulis dapat menarik kesimpulan bahwa Pengembangan Karir PT Bank CIMB Niaga Cabang Pondok Indah sudah sangat memuaskan. Hal ini tergambar pada hasil jawaban dari sebaran kuesioner yang sangat baik, yakni terlihat pada banyaknya jawaban Sangat Setuju sebanyak 127 (39,69\%) dan jawaban Setuju sebanyak 164 (51,25\%). Kinerja karyawan PT Bank CIMB Niaga Cabang Pondok Indah berdasarkan hasil penelitian juga sangat memuaskan. Hal ini tergambar pada hasil jawaban dari sebaran kuesioner yang sangat baik, yakni terlihat pada banyaknya jawaban Sangat Setuju sebanyak 130 $(40,63 \%)$ dan banyaknya jawaban Setuju sebanyak $165(51,56 \%)$.

Pengaruh Pengembangan Karir terhadap Kinerja pada PT Bank CIMB Niaga Cabang Pondok Indah berdasarkan hasil perhitungan diperoleh nilai signifikansi sebesar $0,000<0,05$, sehingga hipotesis $\mathrm{H}_{1}$ diterima. Artinya terdapat pengaruh yang signifikan antara Pengembangan Karir terhadap Kinerja karyawan pada PT Bank CIMB Niaga Cabang Pondok Indah. Pengaruh ini ditunjukkan dengan nilai korelasi sebesar 0,2487 yang termasuk ke dalam kategori Lemah (0,20 0,399).

Pengembangan karir PT Bank CIMB Niaga Cabang Pondok Indah sudah sangat baik. Oleh karena itu, perusahaan sebaiknya dapat mempertahankan Pengembangan Karir PT Bank CIMB Niaga Cabang Pondok Indah demi kemajuan perusahaan. Hasil penelitian menunjukkan kinerja karyawan pada PT Bank CIMB Niaga Cabang Pondok Indah sangat baik. Karyawan seharusnya mampu untuk mempertahankannya demi kemajuan perusahaan sebaiknya karyawan lebih inisiatif mampu bekerja secara mandiri dan mampu memberikan ide-ide terbaik.

Untuk mempertahankan sebaiknya perusahaan meningkatkan pengembangan karir para karyawannya dengan mengaktifkan fungsi penga- wasan dan pemberian reward serta punishment yang objektif serta transparan kepada seluruh karyawan. Dengan demikian karyawan menjadi lebih baik dalam mengoptimalkan waktu dan menyelesaikan pekerjaan pada masa yang akan datang.

\section{PENGHARGAAN}

Pada kesempatan ini penulis mengucapkan terima kasih kepada semua yang terlibat, baik secara langsung maupun tidak langsung yang tidak bisa disebutkan satu persatu. Terima kasih atas saran, masukan, dan bantuan. Semoga penelitian ini bisa bermanfaat bagi semua pihak.

\section{DAFTAR PUSTAKA}

AA. Anwar Prabu Mangkunegara. (2013). Manajemen Sumber Daya Manusia Perusahaan. Bandung: Remaja Rosdakarya.

Amma, Mufida.(2018). Hubungan Pengembangan Karir dengan Kepuasan Kerjaa Pegawai Pada Sub Bagian Tanaman dan Obat Direktorat Jendral Hortikultura Kementrian Pertanian Republik Indonesia. Jurnal Online Mahasiswa (JOM) Bidang Manajemen, 3(3).

Asmalah, Lia. (2019). Manajemen Sumber Daya Manusia. Jakarta: Sahabat Pena.

Dessler, Garry. (2014). Manajemen Sumber Daya Manusia. Jakarta: Salemba Empat.

Dewi, Karina. (2016). Pengaruh Etos Kerja, Insentif Dan Pengembangan Karir Terhadap Kinerja Karyawan Departemen Cutting PT Morichindo Fashion Ungaran. Jurnal Stieama, 8(16).

Handoko, T Hani. (2011). Manajemen, Edisi Kedua. Yogyakarta: BPFE.

Marwansyah. (2012). Manajemen Sumber Daya Manusia. Bandung: Alfabeta.

Mangkunegara, A.A Anwar Prabu. (2011). Manajemen Sumber Daya Manusia Perusahaan, Cetakan Kesepuluh. Bandung: PT Remaja Rosdakarya.

Marnisah, Luis. (2019). Hubungan Industrial dan Kompensasi. Jakarta: Deepublish.

Sari, N, Novitri. (2016). Pengaruh Pengembangan Karir Terhadap Kinerja Karyawan PT PLN 
(Persero) Wilayah Kalimantan Utara Sektor Pembangkit Mahakam Samarinda. Ejurnal Administrasi Bisnis, 4(2). 620-630.

Sudjamitko. Steve. (2009). Mengapa Departemen SDM Dibenci. Jakarta: Gramedia Pustaka Utama.

Sugiyono. (2007). Metode Penelitian Kuantitatif Kualitatif dan R\&D. Bandung: Alfabeta.

Sunyoto, D. (2012). Manajemen Sumber Daya Manusia. Yogyakarta: CAPS.
Putu Ni Luh. (2016). Pengaruh Pengembangan Karir terhadap Kinerja Karyawan melalui Mediasi Motivasi kerja pada karya mas ART GALLERY. E-Jurnal Manajemen Unud, 5(9). Wardhana. Indra (2015). Pengaruh Motivasi, Insentif, dan Pengembangan Karir Terhadap Kinerja Karyawan PT Telkomsel Grapari Pemuda Surabaya. Ejurnal Ilmu Manajemen MAGISTRA, 1(2). 